\title{
Type 2 diabetes mellitus and skeletal muscle metabolic function.
}

Citation for published version (APA):

Phielix, E., \& Mensink, M. (2008). Type 2 diabetes mellitus and skeletal muscle metabolic function.

Physiology \& Behavior, 94(2), 252-258. https://doi.org/10.1016/j.physbeh.2008.01.020

Document status and date:

Published: 01/01/2008

DOI:

10.1016/j.physbeh.2008.01.020

Document Version:

Publisher's PDF, also known as Version of record

Document license:

Taverne

Please check the document version of this publication:

- A submitted manuscript is the version of the article upon submission and before peer-review. There can be important differences between the submitted version and the official published version of record.

People interested in the research are advised to contact the author for the final version of the publication, or visit the DOI to the publisher's website.

- The final author version and the galley proof are versions of the publication after peer review.

- The final published version features the final layout of the paper including the volume, issue and page numbers.

Link to publication

\footnotetext{
General rights rights.

- You may freely distribute the URL identifying the publication in the public portal. please follow below link for the End User Agreement:

www.umlib.nl/taverne-license

Take down policy

If you believe that this document breaches copyright please contact us at:

repository@maastrichtuniversity.nl

providing details and we will investigate your claim.
}

Copyright and moral rights for the publications made accessible in the public portal are retained by the authors and/or other copyright owners and it is a condition of accessing publications that users recognise and abide by the legal requirements associated with these

- Users may download and print one copy of any publication from the public portal for the purpose of private study or research.

- You may not further distribute the material or use it for any profit-making activity or commercial gain

If the publication is distributed under the terms of Article $25 \mathrm{fa}$ of the Dutch Copyright Act, indicated by the "Taverne" license above, 


\title{
Type 2 Diabetes Mellitus and Skeletal Muscle Metabolic Function
}

\author{
Esther Phielix *, Marco Mensink \\ Department of Human Biology, Nutrition and Toxicology Research Institute Maastricht (NUTRIM), Maastricht University, Maastricht, the Netherlands
}

Received 13 August 2007; received in revised form 23 January 2008; accepted 25 January 2008

\begin{abstract}
Type 2 diabetic patients are characterized by a decreased fat oxidative capacity and high levels of circulating free fatty acids (FFAs). The latter is known to cause insulin resistance, in particularly in skeletal muscle, by reducing insulin stimulated glucose uptake, most likely via accumulation of lipid inside the muscle cell. A reduced skeletal muscle oxidative capacity can exaggerate this. Furthermore, type 2 diabetes is associated with impaired metabolic flexibility, i.e. an impaired switching from fatty acid to glucose oxidation in response to insulin. Thus, a reduced fat oxidative capacity and metabolic inflexibility are important components of skeletal muscle insulin resistance. The cause of these derangements in skeletal muscle of type 2 diabetic patients remains to be elucidated. An impaired mitochondrial function is a likely candidate. Evidence from both in vivo and ex vivo studies supports the idea that an impaired skeletal muscle mitochondrial function is related to the development of insulin resistance and type 2 diabetes mellitus. A decreased mitochondrial oxidative capacity in skeletal muscle was revealed in diabetic patients, using in vivo 31 Phosphorus Magnetic Resonance Spectroscopy (31P-MRS). However, quantification of mitochondrial function using ex vivo high-resolution respirometry revealed opposite results. Future (human) studies should challenge this concept of impaired mitochondrial function underlying metabolic defects and prove if mitochondria are truly functional impaired in insulin resistance, or low in number, and whether it represents the primary starting point of pathogenesis of insulin resistance, or is just an other feature of the insulin resistant state.
\end{abstract}

(C) 2008 Elsevier Inc. All rights reserved.

Keywords: Type 2 diabetes; Insulin resistance; Muscle metabolic function; Mitochondrial function

\section{Introduction}

The incidence of type 2 diabetes mellitus is rapidly increasing and is reaching endemic proportions. It is estimated that currently worldwide 190 million people suffer from diabetes, with a predicted increase to 300 million in 2025 [1,2]. Two key features in the pathogenesis of type 2 diabetes mellitus are a decreased ability of insulin to perform its normal physiological role, insulin resistance [3], and the inability of the pancreatic $\beta$-cell to adequately secrete insulin, $\beta$-cell failure [4]. It is well recognized that fatty acid metabolism plays an important role in the development of insulin resistance and type

\footnotetext{
* Corresponding author. Nutrition and Toxicology Research Institute Maastricht (NUTRIM), Department of Human Biology, Maastricht University, P.O. Box 616, 6200 MD Maastricht. Tel.: +31 43 3884258; fax: +31 43 3670976.

E-mail address: esther.phielix@hb.unimaas.nl (E. Phielix).
}

2 diabetes mellitus [5]. Evidence is now accumulating that ectopic lipid accumulation -i.e. lipid deposition in non-adipose tissue - is a central feature of the disease. Recently the role of mitochondria has gained interest in explaining the disturbed fatty acid metabolism and insulin resistance in type 2 diabetes, especially in skeletal muscle. In this review, we will discuss the metabolic defects in type 2 diabetes mellitus and address the role of skeletal muscle mitochondrial function.

\section{Insulin resistance}

The two most important organs affected by insulin resistance are liver and skeletal muscle. Type 2 diabetes is characterized by an increased postabsorptive ('basal') hepatic glucose production (HGP) and a reduced ability of insulin to suppress HGP (hepatic insulin resistance), which contributes to hyperglycemia [6]. In healthy individuals, an increased gluconeogenesis is compensated by a decreased glycogenolysis, due to concomitant hyperinsulinemia, thereby maintaining hepatic glucose output at 
the same level (so-called 'hepatic autoregulation') [7,8]. In type 2 diabetes, a breakdown of this hepatic autoregulation is suggested to underlie the increased hepatic glucose output [9]. Increased circulating plasma free fatty acids (FFA) are implicated in these defects in hepatic glucose metabolism (for review see [10]).

Skeletal muscle is responsible for the major part $(>80 \%)$ of insulin-stimulated whole body glucose disposal, and hence plays an important role in the pathogenesis of insulin resistance. There is ample evidence showing that an acute increase in plasma FFA, via intravenous lipid infusion, can induce skeletal muscle insulin resistance in non-diabetic and diabetic subjects (see for review [11]), while an acute lowering of elevated plasma FFA levels lowered insulin resistance in obese diabetic and non-diabetic subjects [12]. Several mechanisms have been proposed to explain the mechanism responsible for these FFA-induced defects. The glucose fatty-acid cycle as postulated by Randle, coupled an increased lipid availability and fat oxidation to a decreased glucose uptake and oxidation [5]. Although the Randle cycle is a valid physiological principle, many observations now argue against a role for the glucose fatty-acid cycle in explaining fatty acidinduced insulin resistance in skeletal muscle [13-16], and suggest that FFA primarily inhibit glucose transport and not glycolysis.

An increased accumulation of triacylglycerol within skeletal muscle (intramyocellular lipid, IMCL) is closely related to the degree of insulin resistance [17-19]. Evidence, however, is accumulating that not IMCL itself causes insulin resistance, but rather some other lipid metabolites associated with intramuscular triacylglycerol, i.e. long-chain fatty acyl-CoA (LCFA-CoA), diacylglycerol (DAG) and/or ceramide [20-23]. Thus, accumulation of lipid (metabolites) within the muscle could induce insulin resistance, through direct effects on glucose utilization by altering enzyme activities or through interference with insulin signaling. However, what causes lipid accumulation?

\section{Fat oxidative capacity and metabolic flexibility}

Type 2 diabetic subjects are characterized by a decreased capacity to oxidize fat [24-28]. Sampling skeletal muscle tissue, a diminished oxidative capacity was revealed $[24,29,30]$. The metabolic capacity of insulin resistant skeletal muscle appears to be organized towards fat esterification rather than fat oxidation [29]. A dysbalance between fatty acid uptake and fatty acid oxidation could easily lead to fat accumulation within skeletal muscle, which can, as discussed earlier, induce insulin resistance. Interestingly, we demonstrated that male subjects with milder forms of hyperglycemia (i.e. impaired glucose tolerance, IGT) have the same defects in fatty acid utilization as subjects with type 2 diabetes mellitus [31], suggesting that these disturbances may play an important role in the development of IGT and type 2 diabetes mellitus.

Next to an impaired fasting fat oxidation, skeletal muscle of insulin resistant subjects is characterized by so-called 'metabolic inflexibility' [32]. Thus, healthy lean individuals rely on fat oxidation under fasting conditions and switch easily to carbohydrate oxidation in response to insulin stimulation. This flexibility, however, is lost in the insulin resistant (diabetic) state (see Fig. 1). Metabolic flexibility is positively correlated with insulin sensitivity [33], and anti-diabetic treatment with thiazolidinediones [34], or a program of weight-loss and improved aerobic fitness training [35], is able to improve metabolic flexibility. A state of metabolic inflexibility could contribute to the accumulation of IMCL, and thus contribute to the development of insulin resistance and type 2 diabetes. However, it could also be a reflection of the insulin resistant state, with both carbohydrate and fat oxidation being less sensitive to the normal physiological response of insulin.

To test the hypothesis that metabolic switching is an intrinsic characteristic of skeletal muscle, Ukropcova et al [33] performed series of in vitro experiments in myotubes grown from healthy human volunteers, in which dynamic changes of fat oxidation were evaluated. The capacity of glucose to suppress fat oxidation ('suppressibility'), and palmitate to increase fat oxidation ('adaptability') was measured and correlated to in vivo insulin sensitivity and metabolic flexibility. Suppressibility was inversely correlated with insulin sensitivity and metabolic flexibility, while adaptability was positively correlated with both metabolic characteristics [33]. From this, it was concluded that metabolic switching is an intrinsic property of skeletal muscle. This leaves the question what cellular defects can underlie the metabolic inflexibility and the reduced fat oxidative capacity seen in skeletal muscle of insulin resistant subjects. In a recent paper it was revealed that metabolic inflexibility and reduced mitochondrial mass clustered together in subjects with a family history of diabetes [36], supporting the role of intrinsic skeletal muscle metabolic defect in the pathogenesis of insulin resistance and diabetes, and suggesting that proper mitochondrial function seems crucial.

\section{Impaired skeletal muscle mitochondrial function and type 2 diabetes}

In search for the cellular causes of the metabolic disturbances seen in skeletal muscle of insulin resistant subjects, mitochondria

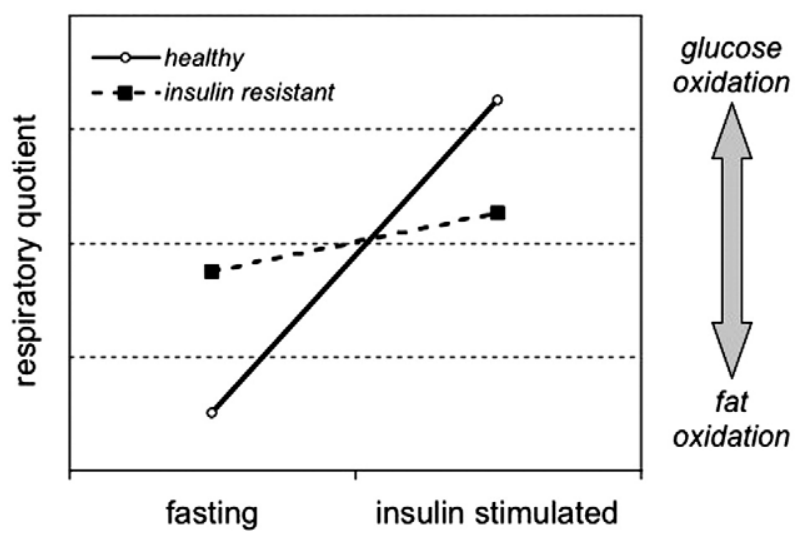

Fig. 1. Metabolic inflexibility. Healthy subjects (solid line) display metabolic flexibility, i.e. heavily rely on lipid as source for substrate oxidation during fasting (low respiratory quotient, RQ) and rapidly switch to glucose oxidation upon insulin-stimulation (high RQ). In contrast, insulin-resistant - metabolic inflexible - subjects display a lower rate of lipid oxidation under fasting conditions (increased RQ), and do hardly increase glucose oxidation upon insulin-stimulation (lower RQ) compared to healthy individuals. (adapted from Kelley and Mandarino [32]). 
are a likely candidate. Mitochondria are at the heart of (cell) life. They provide the energy for almost all cellular processes and are the main oxygen consumer of the body. Proper oxidative substrate utilization and fuel switching require proper mitochondrial function. During the last few years the role of mitochondria in the pathogenesis of insulin resistance and type 2 diabetes has gained interest.

In vivo studies, using non-invasive 31-Phosporus Magnetic Resonance Spectroscopy ( $\left.{ }^{31} \mathrm{P}-\mathrm{MRS}\right)$, point towards an impaired mitochondrial function in type 2 diabetic patients [37,38], firstdegree relatives of type 2 diabetic patients [39], and in elderly [40]. Petersen et al [39] were the first to examine in vivo mitochondrial function in lean, insulin-resistant offspring of patients with type 2 diabetes. Mitochondrial oxidative phosphorylation activity was determined by analyzing saturation transfer between inorganic phosphate and ATP in the resting soleus muscle. A reduced mitochondrial oxidative phosphorylation was found in insulin resistant offspring compared to insulin-sensitive controls, and was associated with an increased IMCL content [39]. Interestingly, they recently revealed that - in a comparable group of insulin-resistant offspring - a reduced mitochondrial density may be involved in decreased mitochondrial function [41].

Similar defects in mitochondrial function as seen in the offspring were found in lean, elderly insulin-resistant subjects [40]. However, in contrast to insulin resistant offspring of type 2 diabetic patients, it is likely that in elderly people an acquired defect in mitochondrial activity, rather than inherited defect, may lead to the decrement in skeletal muscle mitochondrial function. Also using the saturation transfer method, Szendroedi et al [38] observed that diabetic patients had a lower fasting ATP synthetic flux compared to young controls, but not compared to sex-, age-, and body mass index (BMI)-matched controls. However, increased fasting FFA and insulin resistance already characterized these matched control compared to young controls. Insulin stimulation increased ATP synthetic flux in both groups of controls but failed to increase in patients with T2DM. The authors concluded that lipid availability primarily determines fasting ATP flux, whereas insulin sensitivity defines insulin-stimulated ATP flux [38].

We determined in vivo mitochondrial function in the vastus lateralis muscle of type 2 diabetic patients and age and BMImatched normoglycemic control subjects, employing an alternative ${ }^{31} \mathrm{P}-\mathrm{MRS}$ method, i.e. measuring the phosphate creatine (PCr) kinetics during recovery from exercise [42]. During exercise, $\mathrm{PCr}$ content decreases transiently and recovers rapidly after exercise. In the post-exercise state $\mathrm{PCr}$ resynthesis is driven purely oxidatively [43] and the resynthesis rate reflects mitochondrial capacity. An advantage of this method is that mitochondrial function can be assessed under conditions of increased metabolic demand. In short, after a magnetic resonance image is acquired from the upper leg, a non-saturated spectrum is acquired. In this spectrum (see Fig. 2A for a typical example), several peaks can be fitted. Subsequently, a series of spectra is acquired during 2 minutes of rest, 5 minutes of kneeextension exercise and 5 minutes of recovery. Finally, the timecourse of the $\mathrm{PCr}$ amplitude $(\mathrm{PCr}(\mathrm{t}))$ during the last 20 seconds
A

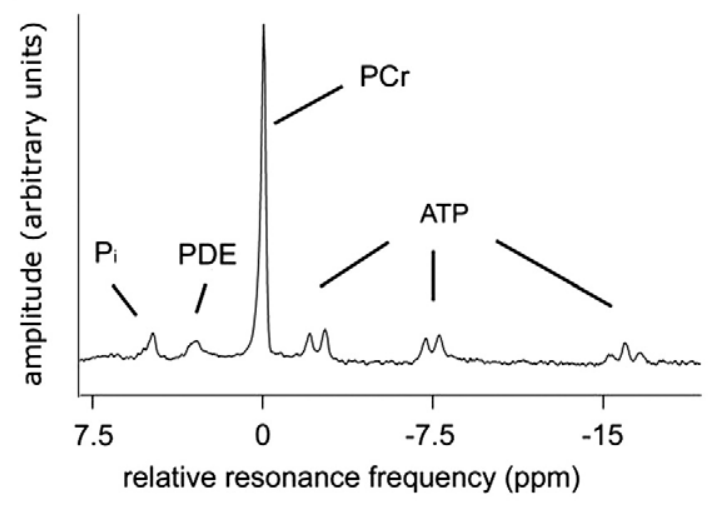

B

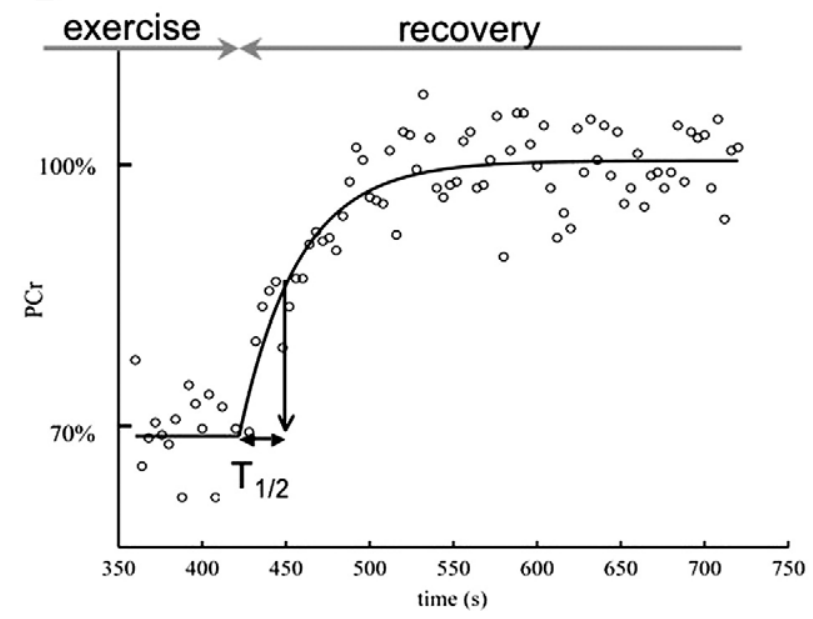

Fig. 2. Measuring in vivo mitochondrial function with ${ }^{31} \mathrm{P}-\mathrm{MRS}$ using an exercise protocol. (A) Typical, ${ }^{31} \mathrm{P}-\mathrm{MR}$ spectrum of the vastus lateralis muscle at rest. The arrows point out inorganic phosphate (Pi), phosphodiester (PDE), creatine phosphate (PCr), and adenosinetriphosphate (ATP). (B) $\mathrm{PCr}$ recovery of an individual patient with the mono- exponential growth preceded by the steady state fitted to the measured data ( $\mathrm{t} 1 / 2=24.9$ seconds) [37].

of exercise (steady state) and during the recovery period is fitted. From the fitted curve, the $\mathrm{T}_{1 / 2}$ of the $\mathrm{PCr}$ recovery halftime is determined (see Fig. 2B), which reflects skeletal muscle mitochondrial oxidative capacity. Using this approach, a $45 \%$ prolonged $\mathrm{PCr}$ half-time was found in type 2 diabetic patients compared to control subjects [37]. PCr half-time correlated positively with plasma glucose concentration in the diabetic population, revealing that the decrease in oxidative capacity is related to the degree of the disease. Interestingly, IMCL content was not different between type 2 diabetic patients and BMImatched control subjects [37]. Furthermore, we found a correlation between $\mathrm{PCr}$ half-time and whole-body maximal oxygen consumption $\left(\mathrm{VO}_{2}-\mathrm{max}\right)$. It is known for long time that $\mathrm{VO}_{2}-\mathrm{max}$ is reduced in diabetic subjects [44]. Our data indicate that $\mathrm{VO}_{2}$ max is a good reflection of skeletal muscle mitochondrial oxidative capacity.

Taken together, in vivo data support the hypothesis that an impaired mitochondrial oxidative capacity - or function - is an early factor in the pathogenesis of type 2 diabetes. Although oxygen consumption takes place at the level of the mitochondria, cardiac output, oxygen transport through the circulation, skeletal 
muscle capillary density and perfusion, as well as a reduced mitochondrial content and a real intrinsic mitochondrial dysfunction (i.e. lower respiratory capacity per mitochondrion) can all affect skeletal muscle mitochondrial oxidative capacity. The question remains whether a true mitochondrial dysfunction underlies the impaired skeletal muscle metabolic function seen in first-degree relatives and diabetic patients, and whether this is explained by a reduced mitochondrial density or functional impaired mitochondria.

\subsection{Intrinsic mitochondrial aberrations in type 2 diabetes?}

The group of Kelley was the first to report an impaired activity of marker enzymes of oxidative pathways in skeletal muscle from individuals with obesity and type 2 diabetes [45]. These findings raised the possibility of true impaired mitochondrial function involved in the pathogenesis of insulin resistance. They also showed lowered activity of NADH: $\mathrm{O}_{2}$ oxidoreductase, reflecting over-all activity of the electron transport chain (ETC), and of citrate synthase, indicative of mitochondria content, in type 2 diabetic patients compared to obese and lean control subjects [46]. These findings suggested that an impaired functional capacity of mitochondria might contribute to the disturbances in substrate metabolism as seen in muscle of diabetic patients. In the same study, size and morphology of skeletal muscle mitochondria were assessed using electron microscopy [46]. It was revealed that mitochondria were smaller in obese and type 2 diabetic subjects compared to lean controls, with the mitochondrial longitudinal area positively correlating with insulin sensitivity. Furthermore, only in muscle of obese and type 2 diabetic individuals enlarged fractured mitochondria were found [46]. In a more recent study [47] it was reported that mitochondrial function was especially impaired in the subsarcolemmal fraction of mitochondria, and, interestingly, mitochondrial function was still significantly decreased after normalization for mitochondrial content in obese and type 2 diabetic individuals, indicating a true functional impairment.

To further examine if mitochondrial aberrations were due to intrinsic defects or a reduction in mitochondrial content, a few studies were performed in which mitochondrial function was normalized for mitochondrial content, using citrate synthase activity or mitochondrial copy DNA number (mtDNA). After normalization, some studies indeed revealed a functional impairment in mitochondria of type 2 diabetic patients $[47,48]$, while other studies found no differences [46,49]. Citrate synthase activity is often used as a marker for mitochondrial content, the activity of this enzyme, however, reflects both mitochondrial mass and mitochondrial enzyme activity. Furthermore, reduced activity of oxidative enzymes does not necessarily reflect mitochondrial function, because only part of the mitochondrial oxidative system is studied. Moreover, this is done out of its functional context, i.e. activity of single complexes of the ETC are often measured independent of the control of the oxidative phosphorylation system that is present in functional mitochondria. Therefore, true functional mitochondrial impairments should be studied using polarografic respiratory measurements in isolated mitochondria or permeabilized muscle fibers.
Two recent studies explored enzyme capacities of the ETC using respirometry measurements $[48,49]$. Oxygen consumption of intact mitochondria can be determined in presence of substrates or inhibitors of the ETC complexes. In this way, oxygen consumption coupled to substrate oxidation and energy production can be evaluated. When uncoupling agents of the ETC are added, the proton gradient over the inner mitochondrial membrane is lost and oxygen consumption is maximized to compensate for this loss of gradient. In this way, maximal ETC enzyme capacity can be measured.

Using such an approach, a decreased mitochondrial function, was seen in type 2 diabetic patients compared to control subjects [48], as measured in isolated mitochondria. These data provided evidence for a functional impairment in mitochondrial respiration related to type 2 diabetes. However, another study observed a lower ADP-stimulated state 3 respiration and a lower uncoupled respiration in permeabilized muscle fibers from type 2 diabetic patients [49]. After normalization for citrate synthase differences were no longer found compared to matched control subjects [49]. From this data it was concluded that mitochondrial function is normal in type 2 diabetes and that the observed blunted coupled and uncoupled respiration can be attributed to lower mitochondrial content. A reason for the discrepancy in the results of both $e x$ vivo studies may be the different methods used to assess mitochondrial oxygen consumption, i.e. isolated mitochondria vs permeabilized fibers. Isolated mitochondria loose their interaction with the cytoplasm in contrast to permeabilized muscle fibers, in which the mitochondria are kept in their native environment. In addition, permeabilized muscle fibers have some endogenous substrates left, in contrast to isolated mitochondria, which can also influence the outcome in mitochondrial function.

More research is needed to investigate whether the impaired mitochondrial oxidative phosphorylation and ETC capacity in type 2 diabetes can fully accounted for by a diminished mitochondrial content, or reflects (also) a functional impairment in mitochondria.

\section{2. $P G C-1 \alpha$ and mitochondrial function}

Which factors - inherited or acquired - could be responsible for the reduced mitochondrial function in insulin resistant skeletal muscle? The peroxisome proliferator-activated receptor- $\gamma$ coactivator $1 \alpha(\mathrm{PGC}-1 \alpha)$ is a likely candidate. PGC- $1 \alpha$ supports the transcriptional activity of nuclear respiratory factors (NRFs), which regulate the transcription of genes involved in oxidative metabolism (OXPHOS), and stimulate mtTFA, a key transcriptional factor for the mitochondrial genome. Therefore, as a result of a reduced level of PGC-1 $\alpha$ in insulin resistant states, a reduction in mitochondrial function can be anticipated. Indeed, two DNA microarray studies [50,51] revealed a lowered expression of a set of genes involved in oxidative phosphorylation under control of PGC- $1 \alpha$, as well as PGC- $1 \alpha$ itself, in skeletal muscle of type 2 diabetic patients [50,51] and offspring of type 2 diabetic parents [50]. The association between PGC$1 \alpha$ and diabetes is further established by studies revealing an association between polymorphisms PGC-1 $\alpha$ and an increased risk on diabetes $[52,53]$. 
In accordance with the microarray studies, we showed an approximately $60 \%$ reduction in PGC- $1 \alpha$ mRNA level in skeletal muscle of type 2 diabetic patients compared with BMI and age-matched controls [34]. In addition, PGC-1 $\alpha$ expression restored after treatment with the anti-diabetic agent Rosiglitazone together with an improvement in muscular insulin sensitivity, and an improved metabolic function [34]. In contrast, Morino et al [41] found no differences in PGC- $1 \alpha$ expression or in the expression of transcription factors controlled by PGC- $1 \alpha$ (e.g. NRFs, mtTFA) between insulin resistant offspring of type 2 diabetic parents and BMI and age-matched control subjects, although mitochondrial content was decreased in offspring. Multiple genetic and environmental factors (e.g. physical activity, age) can influence the expression of PGC-1 $\alpha$ [54]. This could have influenced the results, as Morino et al [41] measured young, lean subjects, in contrast to the middle-aged, overweight participants measured in studies showing a reduced PGC-1 $\alpha$ expression [34,50,51]. However, it cannot be excluded that other mechanisms than regulation by PGC- $1 \alpha$ are responsible for the reduced mitochondrial content in lean, insulin resistant offspring.

\subsection{Mitochondrial dysfunction: cause or consequence?}

Many studies point towards a reduced mitochondrial oxidative capacity -or function- as an important feature of type 2 diabetes mellitus. A series of events can be proposed to explain mitochondrial dysfunction and the increased insulin resistance observed in skeletal muscle of patients with type 2 diabetes mellitus (see Fig. 3). The reduced mitochondrial function observed in young, lean offspring of type 2 diabetic patients [39], makes it likely to be an early event, and therefore a potential primary cause of type 2 diabetes mellitus, as offspring of type 2 diabetic patients are at increased risk to develop the disease. However, although not hyperglycemic, offspring of type 2 diabetic patients are already characterized by many of the metabolic derangements seen in type 2 diabetes: insulin resistance [39], hyperinsulinaemia [39], metabolic inflexibility [36], increased skeletal muscle lipid accumulation [19,39] and - sometimes increased circulating FFA levels [19]. This makes it still possible that the reduced mitochondrial function as seen in offspring is consequence of the (pre)diabetic insulin-resistant state rather than cause. Moreover, Asmann et al [55] compared mtDNA copy number, indicative of mitochondrial content, and skeletal muscle ATP production between type 2 diabetic patients and non-diabetic controls at similar postabsorptive plasma insulin and glucose concentrations and observed no difference. They concluded that the difference in mitochondrial function between type 2 diabetic patients and nondiabetic subject is attributable to multiple factors related to insulin action rather than an intrinsic metabolic defect [55]. Furthermore, it is suggested that increased lipid accumulation in muscle cells could impair mitochondrial oxidative capacity due to lipid peroxidation-induced damage to mitochondria [56]. This would further exacerbate intramyocellular lipid accumulation. In support of this idea, skeletal muscle of obese insulin resistant subjects, not only contains more lipid, but these lipids did show a higher degree of peroxidation [57].

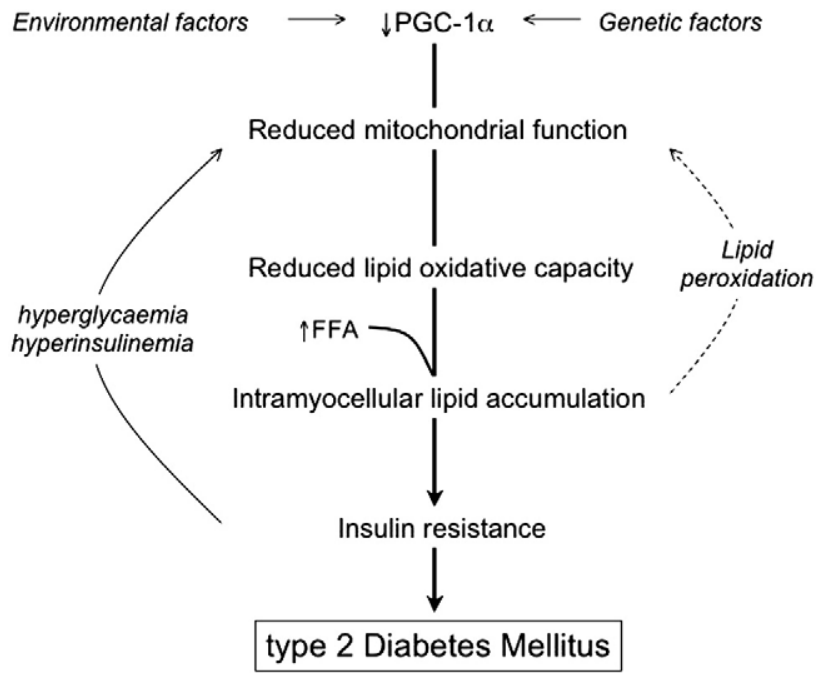

Fig. 3. Proposed series of events explaining skeletal muscle insulin resistance. Both, environmental factors (e.g. physical activity, dietary intake, aging) and genetic factors (e.g. polymorphisms) reduce the expression of genes, controlled of PGC-1a, involved in oxidative metabolism and mitochondrial biogenesis. This will impair mitochondrial function, either due to a reduced mitochondrial density or functional mitochondrial impairment, or both. As a consequence subtle changes in skeletal muscle metabolic function become manifest, i.e. a reduced fasting lipid oxidation rate and metabolic inflexibility. These derangements will contribute, together with an increased delivery of FFA, to an accumulation of lipid inside the muscle cell. Lipid metabolites associated with IMCL, like diacylglycerol (DAG) and fatty acyl-CoA, can activate (certain) $\mathrm{PKC}$ isoforms inducing insulin-resistance, through interference with insulin signaling. The reduced insulin-stimulated skeletal muscle glucose disposal, in concert with an increased hepatic glucose output and failure of the pancreatic $\beta$-cell, contributes to the development of clinically overt type 2 diabetes mellitus. Features of the insulin resistant state, like hyperglyceamia, hyperinsulinaemia and IMCL accumulation can further deteriorate skeletal muscle mitochondrial function, creating a vicious cycle.

However, whether this indeed can affect mitochondrial function needs to be proven.

\section{Conclusion}

Reviewing the existing data, evidence from both in vivo and ex vivo studies supports the idea that an impaired skeletal muscle mitochondrial function is related to the development of insulin resistance and type 2 diabetes mellitus. Future (human) studies should challenge this concept of impaired mitochondrial function and prove if mitochondria are truly functional impaired in insulin resistance, or low in number, and whether it represents the primary starting point of pathogenesis of insulin resistance, or is just an other feature of the insulin resistant state.

\section{References}

[1] King H, Aubert RE, Herman WH. Global burden of diabetes, 1995-2025: prevalence, numerical estimates, and projections. Diabetes Care 1998;21(9): 1414-31.

[2] Zimmet P. Globalization, coca-colonization and the chronic disease epidemic: can the Doomsday scenario be averted? J Intern Med 2000;247(3): 301-10.

[3] Reaven GM. Banting lecture 1988. Role of insulin resistance in human disease. Diabetes 1988;37(12):1595-607. 
[4] Porte Jr D. Banting lecture 1990. Beta-cells in type II diabetes mellitus. Diabetes 1991;40(2):166-80.

[5] Randle PJ, Garland PB, Hales CN, Newsholme EA. The glucose fatty-acid cycle. Its role in insulin sensitivity and the metabolic disturbances of diabetes mellitus. Lancet 1963;1:785-9.

[6] Fery F. Role of hepatic glucose production and glucose uptake in the pathogenesis of fasting hyperglycemia in type 2 diabetes: normalization of glucose kinetics by short-term fasting. J Clin Endocrinol Metab 1994;78(3): 536-42.

[7] Clore JN, Glickman PS, Nestler JE, Blackard WG. In vivo evidence for hepatic autoregulation during FFA-stimulated gluconeogenesis in normal humans. Am J Physiol 1991;261(4 Pt 1):E425-9.

[8] Jenssen T, Nurjhan N, Consoli A, Gerich JE. Failure of substrate-induced gluconeogenesis to increase overall glucose appearance in normal humans. Demonstration of hepatic autoregulation without a change in plasma glucose concentration. J Clin Invest 1990;86(2):489-97.

[9] Boden G, Chen X, Capulong E, Mozzoli M. Effects of free fatty acids on gluconeogenesis and autoregulation of glucose production in type 2 diabetes. Diabetes 2001;50(4): 810-6.

[10] Lam TK, van de Werve G, Giacca A. Free fatty acids increase basal hepatic glucose production and induce hepatic insulin resistance at different sites. Am J Physiol Endocrinol Metab 2003;284(2):E281-90.

[11] Boden G. Free fatty acids, insulin resistance, and type 2 diabetes mellitus. Proc Assoc Am Physicians 1999;111(3):241-8.

[12] Santomauro AT, Boden G, Silva ME, Rocha DM, Santos RF, Ursich MJ. Overnight lowering of free fatty acids with Acipimox improves insulin resistance and glucose tolerance in obese diabetic and nondiabetic subjects. Diabetes 1999;48(9):1836-41

[13] Kelley DE, Mokan M, Simoneau JA, Mandarino LJ. Interaction between glucose and free fatty acid metabolism in human skeletal muscle. J Clin Invest 1993;92(1):91-8.

[14] Roden M, Price TB, Perseghin G, Petersen KF, Rothman DL, Cline GW, et al. Mechanism of free fatty acid-induced insulin resistance in humans. J Clin Invest 1996;97(12):2859-65.

[15] Roden M, Krssak M, Stingl H, Gruber S, Hofer A, Furnsinn C, et al. Rapid impairment of skeletal muscle glucose transport/phosphorylation by free fatty acids in humans. Diabetes 1999;48(2):358-64.

[16] Shulman GI, Rothman DL, Jue T, Stein P, DeFronzo RA, Shulman RG. Quantitation of muscle glycogen synthesis in normal subjects and subjects with non-insulin-dependent diabetes by $13 \mathrm{C}$ nuclear magnetic resonance spectroscopy. N Engl J Med 1990;322(4):223-8.

[17] Pan DA, Lillioja S, Kriketos AD, Milner MR, Baur LA, Bogardus C, et al. Skeletal muscle triglyceride levels are inversely related to insulin action. Diabetes 1997;46(6):983-8.

[18] Krssak M, Falk Petersen K, Dresner A, DiPietro SM, Vogel SM, Rothman DL, et al. Intramyocellular lipid concentrations are correlated with insulin sensitivity in humans: a $1 \mathrm{H}$ NMR spectroscopy study. Diabetologia 1999;42(1):113-6.

[19] Perseghin G, Scifo P, De Cobelli F, Pagliato E, Battezzati A, Arcelloni C, et al. Intramyocellular triglyceride content is a determinant of in vivo insulin resistance in humans: a $1 \mathrm{H}-13 \mathrm{C}$ nuclear magnetic resonance spectroscopy assessment in offspring of type 2 diabetic parents. Diabetes 1999;48(8):1600-6.

[20] Schmitz-Peiffer C. Signalling aspects of insulin resistance in skeletal muscle: mechanisms induced by lipid oversupply. Cell Signal 2000;12(9-10): 583-94.

[21] Itani SI, Ruderman NB, Schmieder F, Boden G. Lipid-induced insulin resistance in human muscle is associated with changes in diacylglycerol, protein kinase C, and IkappaB-alpha. Diabetes 2002;51(7):2005-11.

[22] Cooney GJ, Thompson AL, Furler SM, Ye J, Kraegen EW. Muscle longchain acyl CoA esters and insulin resistance. Ann NY Acad Sci 2002;967:196-207.

[23] Summers SA. Ceramides in insulin resistance and lipotoxicity. Prog Lipid Res 2006;45(1):42-72.

[24] Blaak EE, Van Baak MA, Kemerink GJ, Pakbiers MT, Heidendal GA, Saris WH. Beta-adrenergic stimulation of energy expenditure and forearm skeletal muscle metabolism in lean and obese men. Am J Physiol 1994;267 (2 Pt 1):E306-15
[25] Colberg SR, Simoneau JA, Thaete FL, Kelley DE. Skeletal muscle utilization of free fatty acids in women with visceral obesity. J Clin Invest 1995;95(4):1846-53.

[26] Kelley DE, Simoneau JA. Impaired free fatty acid utilization by skeletal muscle in non-insulin-dependent diabetes mellitus. J Clin Invest 1994;94(6): 2349-56.

[27] Blaak EE, Wagenmakers AJ, Glatz JF, Wolffenbuttel BH, Kemerink GJ, Langenberg CJ, et al. Plasma FFA utilization and fatty acid-binding protein content are diminished in type 2 diabetic muscle. Am J Physiol Endocrinol Metab 2000;279(1):E146-54.

[28] Blaak EE, van Aggel-Leijssen DP, Wagenmakers AJ, Saris WH, van Baak MA. Impaired oxidation of plasma-derived fatty acids in type 2 diabetic subjects during moderate-intensity exercise. Diabetes 2000;49(12):2102-7.

[29] Simoneau JA, Veerkamp JH, Turcotte LP, Kelley DE. Markers of capacity to utilize fatty acids in human skeletal muscle: relation to insulin resistance and obesity and effects of weight loss. FASEB J 1999;13(14):2051-60.

[30] He J, Watkins S, Kelley DE. Skeletal muscle lipid content and oxidative enzyme activity in relation to muscle fiber type in type 2 diabetes and obesity. Diabetes 2001;50(4):817-23.

[31] Mensink M, Blaak EE, van Baak MA, Wagenmakers AJ, Saris WH. Plasma free Fatty Acid uptake and oxidation are already diminished in subjects at high risk for developing type 2 diabetes. Diabetes 2001;50(11): $2548-54$

[32] Kelley DE, Mandarino LJ. Fuel selection in human skeletal muscle in insulin resistance: a reexamination. Diabetes 2000;49(5):677-83.

[33] Ukropcova B, McNeil M, Sereda O, de Jonge L, Xie H, Bray GA, et al. Dynamic changes in fat oxidation in human primary myocytes mirror metabolic characteristics of the donor. J Clin Invest 2005;115(7):1934-41.

[34] Mensink M, Hesselink MK, Russell AP, Schaart G, Sels JP, Schrauwen P. Improved skeletal muscle oxidative enzyme activity and restoration of PGC-1alpha and PPARbeta/delta gene expression upon rosiglitazone treatment in obese patients with type 2 diabetes mellitus. Int J Obes (Lond) 2007;31(8):1302-10

[35] Goodpaster BH, Katsiaras A, Kelley DE. Enhanced fat oxidation through physical activity is associated with improvements in insulin sensitivity in obesity. Diabetes 2003;52(9):2191-7.

[36] Ukropcova B, Sereda O, de Jonge L, Bogacka I, Nguyen T, Xie H, et al. Family history of diabetes links impaired substrate switching and reduced mitochondrial content in skeletal muscle. Diabetes 2007;56(3):720-7.

[37] Schrauwen-Hinderling VB, Kooi ME, Hesselink MK, Jeneson JA, Backes $\mathrm{WH}$, van Echteld CJ, et al. Impaired in vivo mitochondrial function but similar intramyocellular lipid content in patients with type 2 diabetes mellitus and BMI-matched control subjects. Diabetologia 2007;50(1):113-20.

[38] Szendroedi J, Schmid AI, Chmelik M, Toth C, Brehm A, Krssak M, et al. Muscle mitochondrial ATP synthesis and glucose transport/phosphorylation in type 2 diabetes. PLoS Med 2007;4(5):e154.

[39] Petersen KF, Dufour S, Befroy D, Garcia R, Shulman GI. Impaired mitochondrial activity in the insulin-resistant offspring of patients with type 2 diabetes. N Engl J Med 2004;350(7): 664-71.

[40] Petersen KF, Befroy D, Dufour S, Dziura J, Ariyan C, Rothman DL, et al. Mitochondrial dysfunction in the elderly: possible role in insulin resistance. Science 2003;300(5622):1140-2.

[41] Morino K, Petersen KF, Dufour S, Befroy D, Frattini J, Shatzkes N, et al. Reduced mitochondrial density and increased IRS-1 serine phosphorylation in muscle of insulin-resistant offspring of type 2 diabetic parents. $\mathrm{J}$ Clin Invest 2005;115(12):3587-93.

[42] Kemp GJ, Radda GK. Quantitative interpretation of bioenergetic data from $31 \mathrm{P}$ and $1 \mathrm{H}$ magnetic resonance spectroscopic studies of skeletal muscle: an analytical review. Magn Reson Q 1994;10(1):43-63.

[43] Sahlin K, Harris RC, Hultman E. Resynthesis of creatine phosphate in human muscle after exercise in relation to intramuscular $\mathrm{pH}$ and availability of oxygen. Scand J Clin Lab Invest 1979;39(6):551-8.

[44] Regensteiner JG, Sippel J, McFarling ET, Wolfel EE, Hiatt WR. Effects of non-insulin-dependent diabetes on oxygen consumption during treadmill exercise. Med Sci Sports Exerc 1995;27(6):875-81.

[45] Simoneau JA, Kelley DE. Altered glycolytic and oxidative capacities of skeletal muscle contribute to insulin resistance in NIDDM. J Appl Physiol 1997;83(1):166-71 
[46] Kelley DE, He J, Menshikova EV, Ritov VB. Dysfunction of mitochondria in human skeletal muscle in type 2 diabetes. Diabetes 2002;51(10): $2944-50$

[47] Ritov VB, Menshikova EV, He J, Ferrell RE, Goodpaster BH, Kelley DE. Deficiency of subsarcolemmal mitochondria in obesity and type 2 diabetes. Diabetes 2005;54(1):8-14.

[48] Mogensen M, Sahlin K, Fernstrom M, Fernstrom D, Vind BF, BeckNielsen $\mathrm{H}$, et al. Mitochondrial respiration is decreased in skeletal muscle of patients with type 2 diabetes. Diabetes 2007;56(6):1592-9.

[49] Boushel R, Gnaiger E, Schjerling P, Skovbro M, Kraunsoe R, Dela F. Patients with type 2 diabetes have normal mitochondrial function in skeletal muscle. Diabetologia 2007;50(4):790-6.

[50] Patti ME, Butte AJ, Crunkhorn S, Cusi K, Berria R, Kashyap S, et al. Coordinated reduction of genes of oxidative metabolism in humans with insulin resistance and diabetes: Potential role of PGC1 and NRF1. Proc Natl Acad Sci U S A 2003;100(14):8466-71.

[51] Mootha VK, Lindgren CM, Eriksson KF, Subramanian A, Sihag S, Lehar J, et al. PGC-1alpha-responsive genes involved in oxidative phosphorylation are coordinately downregulated in human diabetes. Nat Genet 2003;34(3): 267-73.

[52] Andrulionyte L, Zacharova J, Chiasson JL, Laakso M. Common polymorphisms of the PPAR-gamma2 (Pro12Ala) and PGC-1alpha
(Gly482Ser) genes are associated with the conversion from impaired glucose tolerance to type 2 diabetes in the STOP-NIDDM trial Diabetologia 2004;47(12):2176-84.

[53] Kim JH, Shin HD, Park BL, Cho YM, Kim SY, Lee HK, et al. Peroxisome proliferator-activated receptor gamma coactivator 1 alpha promoter polymorphisms are associated with early-onset type 2 diabetes mellitus in the Korean population. Diabetologia 2005;48(7):1323-30.

[54] Ling C, Poulsen P, Carlsson E, Ridderstrale M, Almgren P, Wojtaszewski $\mathrm{J}$, et al. Multiple environmental and genetic factors influence skeletal muscle PGC-1alpha and PGC-1beta gene expression in twins. J Clin Invest 2004;114(10):1518-26.

[55] Asmann YW, Stump CS, Short KR, Coenen-Schimke JM, Guo Z, Bigelow ML, et al. Skeletal muscle mitochondrial functions, mitochondrial DNA copy numbers, and gene transcript profiles in type 2 diabetic and nondiabetic subjects at equal levels of low or high insulin and euglycemia Diabetes 2006;55(12):3309-19.

[56] Schrauwen P, Hesselink MK. Oxidative capacity, lipotoxicity, and mitochondrial damage in type 2 diabetes. Diabetes 2004;53(6):1412-7.

[57] Russell AP, Gastaldi G, Bobbioni-Harsch E, Arboit P, Gobelet C, Deriaz O, et al. Lipid peroxidation in skeletal muscle of obese as compared to endurance-trained humans: a case of good vs. bad lipids? FEBS Lett 2003;551(1-3):104-6. 